\section{AB0873 US RHEUMATOLOGISTS HAVE MIXED PERCEPTIONS ABOUT MANAGING PATIENTS WITH NON- RADIOGRAPHIC AXIAL SPONDYLOARTHRITIS AND ANKYLOSING SPONDYLITIS}

J. Robinson, L. Price. Advanced Analytics Group, Spherix Global Insights, Exton, USA

Background: Non-radiographic axial spondyloarthropathy ( $\mathrm{nrAxSpA})$ is a relatively new term used to describe patients who clinically appear to have ankylosing spondylitis (AS) but do not exhibit radiographic sacroilitis. Though several biologics are currently FDA approved for the treatment of AS, there are no agents approved for patients in which there is not radiographic evidence of sacroilitis. With several agents under investigation with the hopes of gaining a line-extension label for nr-axSpA, it is important to understand how the current treating rheumatologists view these two diseases and their current and future plans for spondyloarthropathy management.

Objectives: The study sought to (a) evaluate the differences between AS and nraxSpA diagnosis and treatment patterns (b) highlight the challenges clinicians face in managing patients with nr-AxSpa and (c) understand rheumatologists' willingness to use biologic agents to treat nr-AxSpa.

Methods: An independent market analytics firm collaborated with US rheumatologists $(n=98)$ to learn about current and anticipated changes to the management of Ankylosing Spondylitis and Non-radiographic Axial Spondylitis. Participants were administered an online survey, lasting approximately $30 \mathrm{~min}$ in length and respondents were compensated for their professional time. Following the fieldwork, data were analysed in SPSS, a statistical software, to determine significant differences.

Results: $87 \%$ of the surveyed rheumatologists agree that AS and nr-AxSpA are part of a spectrum, and $37 \%$ report that they often find it challenging to differentiate between the two conditions. The majority of the respondents report that they treat these conditions in a very similar manner. In fact, $40 \%$ agree that distinguishing between the two has no relevance to their treatment decisions. Use of biologics is significantly more pronounced in AS ( $56 \%$ vs. $39 \%$, respectively), largely because there is currently no FDA indicated biologic for nr-AxSpA and because many rheumatologists view nr-AxSpA simply as a less severe precursor to AS, where aggressive treatment with a biologic is not warranted. In order to gain reimbursement for a biologic in patients with $\mathrm{nr}-\mathrm{AxSpA}$, rheumatologists frequently classify patients as having AS (as opposed to $\mathrm{nr}-\mathrm{AxSpA}$ ). Although adalimumab is the most frequently prescribed biologic in both conditions, rapid adoption of an IL-17 inhibitor (secukinumab) is occurring in the US market.

Conclusions: There is a need to educate both primary care physicians and rheumatologists about the differences between AS and nr-AxSpA. The official FDA approval of biologic agents in nr-AxSpA is anticipated to lead to more aggressive treatment of these patients earlier in the spectrum.

REFERENCE:

[1] RealTime Dynamix ${ }^{\mathrm{TM}}$ : Anlylosing Spondylitis and Non-radiographic Axial Spondylitis

Disclosure of Interest: None declared

DOI: 10.1136/annrheumdis-2018-eular.7360

\section{AB0874 1 MENTAL HEALTH DISORDERS IN PATIENTS WITH AXIAL SPONDYLOARTHRITIS: INCREASING OUR UNDERSTANDING OF THE DISEASE. RESULTS FROM THE ATLAS-2017}

M. Garrido-Cumbrera ${ }^{1,2}$, V. Navarro-Compan ${ }^{3}$, D. Gálvez-Ruiz ${ }^{1}$, C. DelgadoDominguez $^{1}$, P. Font Ugalde ${ }^{4}$, O. Braçe ${ }^{1}$, P. Zarco ${ }^{5}$, J. Chacón-García ${ }^{1}$, P. Plazuelo-Ramos ${ }^{2} .{ }^{1}$ Universidad de Sevilla, Sevilla; ${ }^{2} \mathrm{CEADE} ;{ }^{3}$ Rheumatology, Hospital La Paz, IdiPaz, Madrid, Madrid; ${ }^{4}$ Medicina, Universidad de Córdoba, Cordova; ${ }^{5}$ Rheumatology, Hospital Fundación Alarcón, Madrid, Spain

Background: Depression and other mental disorders are among the most prevalent comorbidities in patients with axial spondyloarthritis (axSpA).

Objectives: To assess the association between sociodemographic characteristics, disease progression, and mental health comorbidity with risk of mental disorders (RMD).

Methods: in 2016 a sample of 680 axSpA patients was interviewed as part of the Spanish Atlas. To quantify the RMD, GHQ-12 scale was employed. Possible RMD predictors taken into account in the analysis were: sociodemographic characteristics (age, gender, being part of a couple, patient association membership, job status); disease characteristics (BASDAI, spinal stiffness, functional limitation in 18 daily activities; and mental health comorbidities. All clinical variables showed a Cronbach's alpha coefficient guaranteeing the reliability of the scales used. First, a descriptive analysis was employed to describe the sample and study variables. Second, univariate correlation and homogeneity analyses between each predictor (independent variable) and RMD (GHQ-12) were performed.

Results: All variables except educational level and thoracic stiffness showed significant univariant correlation with RMD. BASDAl, functional limitation and age showed higher coefficient $(r=0.543, p<0.001 ; r=0.378, p<0.001 ; r=-0.174$, $\mathrm{p}<0.001$, respectively).

Multiple hierarchical regression analysis showed as sociodemographic variables explained in great detail the $\mathrm{RMD}\left(\mathrm{R}^{2=} 83.2 \%\right)$. By contrast, having established sociodemographic as a control variable, the inclusion of depression and anxiety to the model increased the $R^{2}$ value to just $0.6 \%(p<0.001)$, while the inclusion of variables related to the disease characteristics add $5.5 \%(p<0.001)$ to the GHQ12 punctuation variability. The only variables presenting a significant coefficient different from 0 were BASDAI $(0.52, p<0.001)$ and functional limitation $(0.14$ $p<0.01)$. This suggests that once the sociodemographic and mental commorbidity variables are established, a change in BASDAI levels or functional limitation impacts the GHQ-12 score.

In the stepwise regression analysis, four variables (BASDAI, functional limitation, association membership, cervical stiffness) showed a significant relation to GHQ12 and explained the majority of RMD variability. BASDAI displayed the highest explanatory degree $\left(R^{2}=0.875, p<0.001\right)$.

Abstract AB0874 - Table 1. Sample characteristics ( $n=474$, unless other specified)

\begin{tabular}{|c|c|}
\hline Variables & Values (means $\pm S D$ or percentage) \\
\hline Age, mean $\pm S D$ & $45.43 \pm 10.78$ \\
\hline Sex, No. of men & $233(49.2 \%)$ \\
\hline Hoving a couple, No. of participonts ( $\mathrm{N}=444$ ) & $386(86.9 \%)$ \\
\hline Education level, No. of university studies & $185(39.3 \%)$ \\
\hline Job stotus, No. of unemployed & $68(14.4 \%)$ \\
\hline Associotion Membership & $227(47.9 \%)$ \\
\hline BASDAl, $(0-10)$ mean $\pm S D(\mathrm{~N}=442)$ & $5.49 \pm 2.17$ \\
\hline Cervical stiffness, No. ( $\mathrm{N}=447)$ & $201(45.0 \%)$ \\
\hline Thoracic stiffness No. (N=435) & $186(42.8 \%)$ \\
\hline Lumbar stiffness No. (N=458) & $288(62.9 \%)$ \\
\hline Functional Limitation, (0-54) mean $\pm S D(\mathrm{~N}=473)$ & $27.54 \pm 12.78$ \\
\hline Depression No. (\%) (N=474) & $99(20.9)$ \\
\hline Anxiety, No. (\%) $(\mathrm{N}=474)$ & $134(28.3)$ \\
\hline$G H Q-12,(0-36)$ mean $\pm S D$ & $18.30 \pm 8.01$ \\
\hline
\end{tabular}

Conclusions: In axSpA, patients at certain sociodemographic levels are more prone to present a higher BASDAI. Taking these conditions for granted, the degree of disease progression measured by BASDAl is a good indicator of RMD. Therefore, in those patients with higher disease activity, psychiatric evaluation and intervention should be considered within the medical treatment.

Acknowledgements: The Atlas was promoted by CEADE and funded by Novartis

Disclosure of Interest: None declared

DOI: 10.1136/annrheumdis-2018-eular.7240

\section{AB0875 QUALITY OF LIFE IMPROVEMENT IN PATIENTS WITH AXIAL SPONDYLOARTHRITIS TREATED WITH NSAIDS AND BIOLOGICAL THERAPY FROM THE PATIENT'S PERSPECTIVE: RESULTS FROM THE ATLAS-2017}

M. Garrido-Cumbrera ${ }^{1,2}$, D. Gálvez-Ruiz ${ }^{1}$, J. Gratacós ${ }^{3,4}$, C. Blanch Mur ${ }^{5}$, V. Navarro-Compán $6 .{ }^{1}$ Universidad de Sevilla, Sevilla; ${ }^{2}$ CEADE, Madrid; ${ }^{3}$ Rheumatology, Hospital Universitari Parc Taulí, Sabadell; ${ }^{4}$ I3PT, UAB; ${ }^{5}$ Novartis, Barcelona; ${ }^{6}$ Rheumatology, Hospital Universitario La Paz, IdiPaz, Madrid, Spain

Background: In patients with axial spondyloarthritis (axSpA), the main long-term outcome is quality of life. Clinical trials and observational studies have shown the efficacy of biological therapy (BT) on improving the signs and symptoms of the disease. However, data assessing the impact of BT on quality of life is scarce and mainly comes from clinical trials. 
Objectives: To assess in clinical practice the improvement in quality of life from the patient's perception as a result of pharmacological treatments in axSpA. Methods: A sample of 680 patients diagnosed with axSpA was interviewed through an online survey as part of the Spanish Atlas-2017, which aimed to promote early referral, improve healthcare, and the use of effective treatments in patients with axSpA. For this study, self-reported data from patients who had received both NSAIDs and BT were analysed. Patients were asked about the improvement they had experienced on 7 different aspects of quality of life after starting treatment with NSAIDs or BT: independence, leisure and free time, social relations, sport and physical activity, and mood and sexual relations. Improvements were measured on a 0 to 10 Likert Scale and classified as low $(\leq 5)$ and high $(\geq 6)$. Non-parametric (Wilcoxon) tests were used to compare the degree of improvement between patients with biological therapy and those with NSAIDs.

Results: A total of 189 patients who had received both types of drugs were included. The mean (SD) age was $44.03( \pm 10.11)$ years, $50.3 \%$ were females, $70.9 \%$ married and $47.1 \%$ belong to a patients' association. The mean (SD) disease duration was $21.3 \pm 10.7$ years and $67.7 \%$ were HLA-B27+. A higher percentage of patients perceived a high level of improvement after receiving a BT than after receiving an NSAID, for both overall quality of life assessment $(57 \%$ vs $22 \%$, respectively) and the different quality of life-related aspects. Additionally, the mean degree of improvement for overall quality of life assessment and the different aspects related to this were reported to be significantly higher after receiving BT than after NSAIDs (overall improvement: $5.46 \pm 2.59$ vs $3.19 \pm 2.45 ; p<0.001$, respectively).

Abstract AB0875 - Table 1. Mean improvement degree and percentage of patients who reported high improvement $(>6$ in $0-10)$ in different aspects related to quality of life after receiving biological therapy and NSAIDs

\begin{tabular}{|l|c|c|c|c|l|}
\hline & \multicolumn{2}{|c|}{ NSAID } & \multicolumn{2}{c|}{ Biological Therapy } & \\
\hline & $\begin{array}{c}\text { High } \\
\text { improvement } \\
(\%)\end{array}$ & $\begin{array}{c}\text { Degree of } \\
\text { improvement, } \\
\text { Mean (SD) }\end{array}$ & $\begin{array}{c}\text { High } \\
\text { improvement } \\
(\%)\end{array}$ & $\begin{array}{c}\text { Degree of } \\
\text { improvement, } \\
\text { Mean (SD) }\end{array}$ & $\begin{array}{c}\text { p value } \\
\text { Wilcoxon }\end{array}$ \\
\hline Independence & 22.6 & $3.40(2.79)$ & 53.0 & $5.83(3.01)$ & $<0.001$ \\
\hline Leisure \& Spare Time & 22.9 & $3.41(2.73)$ & 58.2 & $5.81(2.80)$ & $<0.001$ \\
\hline Employment & 20.7 & $3.01(2.84)$ & 53.6 & $5.48(3.36)$ & $<0.001$ \\
\hline Social Relations & 19.4 & $3.05(2.50)$ & 52.1 & $5.45(2.95)$ & $<0.001$ \\
\hline $\begin{array}{l}\text { Sport \& Physical } \\
\text { Activity }\end{array}$ & 14.4 & $2.62(2.71)$ & 41.3 & $4.88(3.05)$ & $<0.001$ \\
\hline Emotional Wellbeing & 17.4 & $2.70(2.83)$ & 53.9 & $5.78(2.88)$ & $<0.001$ \\
\hline Sexual Activity & 16.0 & $2.52(2.66)$ & $53.4)$ & $4.65(3.28)$ & $<0.001$ \\
\hline Global & 22.2 & $3.19(2.45)$ & 57.0 & $5.46(2.59)$ & $<0.001$ \\
\hline
\end{tabular}

Conclusions: In clinical practice, patients' self-reported satisfaction overall and related to different aspects of quality of life is substantially greater after being treated with BT than with NSAIDs. However, these results need to be confirmed in a longitudinal study

Acknowledgements: The Atlas was promoted by CEADE and funded by Novartis

Disclosure of Interest: M. Garrido-Cumbrera: None declared, D. Gálvez-Ruiz: None declared, J. Gratacós: None declared, C. Blanch Mur Employee of: Novartis, V. Navarro-Compán: None declared

DOI: 10.1136/annrheumdis-2018-eular.7307

\section{AB0876 CORRELATION BETWEEN FAECAL CALPROTECTIN LEVELS AND TOBACCO USE IN PATIENTS WITH SPONDYLOARTHRITIS AND WITHOUT PREVIOUS DIAGNOSIS OF INFLAMMATORY BOWEL DISEASE}

M. Espinosa Malpartida ${ }^{1}$, C. Ramos Giráldez ${ }^{1}$, C. Merino Argumánez ${ }^{1}$, M.B. RuizAntorán², J. Campos Esteban ${ }^{1}$, C. Barbadillo Mateos ${ }^{1}$, H. Godoy Tundidor ${ }^{1}$, B. Agudo Castillo ${ }^{3}$, Y. González Lama ${ }^{3}$, J.L. Andreu Sánchez ${ }^{1}$, J. Sanz Sanz ${ }^{1}$. ${ }^{1}$ Rheumatology; ${ }^{2}$ Clinical Pharmacology; ${ }^{3}$ Digestive, H. U. Puerta de Hierro Majadahonda, Madrid, Spain

Background: It is estimated that between $5 \%$ and $10 \%$ of patients with spondyloarthritis (SpA) are associated with inflammatory bowel disease (IBD). It has also been proven through endoscopic and histological studies that up to $60 \%$ of patients with SpA have microscopic inflammatory intestinal lesions, with a subclinical character and of which the true clinical relevance is unknown, although a greater percentage of these are those that will evolve to IBD.
Objectives: To assess whether tobacco use may be associated with higher faecal calprotectin (FC) levels in patients with diagnosis of SpA and without clinical suspicion or previous diagnosis of IBD.

Methods: TThis is a single centre, cross-sectional, observational study with prospective collecting data. Data were included for consecutive patients from Rheumatology consultation who had been previously diagnosed of SpA, fulfilled ASAS criteria and without digestive symptoms suggestive of IBD (chronic diarrhoea, rectal bleeding, perianal disease, chronic abdominal pain - persistent or recurrent) Details about demographic characteristics, clinical and laboratory variables related with SpA (BASDAI, HLA B27, acute phase reactants), treatments and FC were collected. A pathological cut-off point of $\mathrm{FC}>50 \mathrm{mg} / \mathrm{kg}$ was determined. Patients on NSAIDs treatment were advised to discontinue its use 2 weeks before collecting stool samples. This study was approved by the Clinical Research Ethics Committee.

Results: 99 patients were included: $53.5 \%$ women, with a mean age of $46 \pm 11$ years. nonspecific digestive disorders (dyspeptic symptoms, $\mathrm{H}$. pylori y gastroesophageal reflux) were observed in $9 \%$ of the patients. Among all, $18 \%$ were smokers. Mean BASDAI was $3.7 \pm 2.5 ; 39 \%$ of patients were being treated with any concomitant DMARD and $67 \%$ were on NSAIDs. $49.5 \%$ of the patients ${ }^{49}$ showed elevated FC determinations, with an mean level of $276 \mathrm{mg} / \mathrm{kg}$ (range 52$3,038)$. The percentage of patients with high levels of FC was significantly increased in smokers $(72.2 \%$ vs. $44.4 \%$, p. 0.033$)$, with higher levels of $F C$ in smokers than non-smokers (262 mg/L vs. $121 \mathrm{mg} / \mathrm{L}$. p. 0.126). The remaining analysed variables did not show any significant differences in terms of FC levels. Conclusions: Microscopic bowel inflammation is described in approximately $50 \%$ of patients with SpA and it is related with more severe disease. Tobacco use has been associated with worse prognosis and response to treatment in SpA. A relationship between elevated FC levels (inflammatory activity biomarker) and tobacco use in patients with SpA without previous diagnosis or clinical suspicion of IBD is established in this study.

Disclosure of Interest: None declared

DOI: 10.1136/annrheumdis-2018-eular.5979

\section{AB0877 \\ ANALYSIS OF THE ASSOCIATION OF THE PERIPHERAL INVOLVEMENT OF THE SPONDYLOARTHRITIS WITH THE EXTRA-ARTICULAR MANIFESTATIONS}

M.D.S. Mastella, I.M.S. Vale, M.M. Pereira, M.J. Carmo, G.R.W. Castro, I. A. Pereira. UNISUL, Florianópolis, Brazil

Objectives: Patients with SpA present peripheral involvement, such as arthritis and enthesitis, or only axial involvement, such as sacroiliitis and sindesmophytes The differentiation of the peripheral and axial presentation is important, being able to guide different therapeutic strategies.

Methods: This is a retrospective observational study, conducted in two clinics in Florianópolis. The population was composed of patients with AS and non-radiographic and peripheral axial SpA, according to the criteria of modified New York and ASAS group, respectively, served from 1997 to 2017.

Results: 153 patients were analysed, 82 were male (53.59\%), $71.29 \%$ were HLA B27 positive (77/108 tested), $87.3 \%$ had sacroiliitis detected on $\mathrm{x}$-ray, CT or MRI 104 presented peripheral involvement $(67.97 \%)$ and $49(32.02 \%)$ purely axial involvement. Arthritis occurred in $86(56.2 \%)$ and enthesitis in $57(37.3 \%)$ patients. The use of synthetic DMARD occurred in $78.4 \%$ of the patients, more frequently in the group with peripheral involvement, with methotrexate being used in $74 \%$ versus $56.3 \%$ of those with purely axial involvement $(p<0.05)$. The use of biological DMARD occurred in 104 (68\%), in the majority of the anti-TNF class (96.1\%), with the highest frequency of use in patients with axial involvement $(77.1 \%$ versus $64.4 \%)$, but not statistically significant $(p>0.05)$. Extra-articular manifestations were found in $72(47.1 \%)$ of the patients, with uveitis being the most frequent (26.8\%). The presence of uveitis occurred in $68.3 \%$ of patients with isolated axial involvement versus $31.7 \%$ of patients with peripheral involvement $(p=0.179)$. The cutaneous involvement occurred in $18.3 \%$ of the patients with peripheral involvement compared to $8.3 \%$ of those with an isolated axial condition. Regarding bowe involvement and cardiovascular impairment, there was no significant difference in prevalence between the two groups.

Conclusions: Extra-articular manifestations are frequent in $\mathrm{SpA}$, but are not more frequent in patients with peripheral involvement versus patients with pure axial involvement. Peripheral involvement is associated with greater use of synthetic DMARDs when compared to pure axial involvement.

Disclosure of Interest: None declared

DOI: 10.1136/annrheumdis-2018-eular.1652 